\title{
Determing an "autoimmune" phenotype in systemic JIA
}

N Fischer, B Huegle, JP Haas*

From 18th Pediatric Rheumatology European Society (PReS) Congress

Bruges, Belgium. 14-18 September 2011

\section{Background}

Data from research, clinics and response to treatment point out to an autoinflammatory pathogenesis in Systemic onset Juvenile Idiopathic Arthritis (SoJIA). However a subgroup of patients present with chronic active course of disease, destructive polyarthritis and produc- tion of autoantibodies (CAPA-subtype) not responsive to anti IL-1 treatment.

\section{Aim}

Determine phenotypic characteristics of the CAPA-subtype of SoJIA.

\begin{tabular}{|c|c|c|c|c|}
\hline SoJlA-Patients & 35 & & & \\
\hline \multirow[t]{2}{*}{ Observation (month) } & \multicolumn{4}{|c|}{ mean 69 (range 1-262) } \\
\hline & $\mathrm{n}$ & $\%$ & $n$ & $\%$ \\
\hline \multirow[t]{2}{*}{ Autoantibodies } & pos & & neg & \\
\hline & 9 & 25,7 & 26 & 74,3 \\
\hline ANA & 6 & 17,1 & & \\
\hline RF & 2 & 5,7 & & \\
\hline \multirow[t]{2}{*}{ ANCA } & 3 & 8,6 & & \\
\hline & percen & & & \\
\hline male & 3 & 33,3 & 11 & 42,3 \\
\hline female & 6 & 66,6 & 15 & 57,7 \\
\hline onset age (years) & 6,03 & & 3,54 & \\
\hline relapses & 4 & & 3,6 & \\
\hline joints at onset & 2,1 & & 3,1 & \\
\hline joints when AK pos & 7 & & & \\
\hline MAS & 1 & & 1 & \\
\hline Carditis & 6 & 66,7 & 13 & 50 \\
\hline SAA & 2 of 4 & & 8 of 12 & \\
\hline Amyloidosis & 1 & & 1 & \\
\hline
\end{tabular}

\footnotetext{
* Correspondence: haas.johannes-peter@rummelsberger.net

Deutsches Zentrum für Kinder- und Jugendrheumatologie, Garmisch-

Partenkirchen, Germany
} 


\section{Methods}

Retrospective analysis in a cohort of 35 SoJIA patients well characterized according clinical course and ANA, Rheumatic factor and ANCA.

\section{Results}

Autoantibodies have been found in $25,7 \%$ of the patients, with ANA being the most frequent auto-AK (table 1). There was a significant difference according the age of onset. Moreover females and carditis have been observed more frequently in the AK-pos. group.

\section{Conclusion}

There is evidence for an autoimmune course of disease in SoJIA in a subset of patients with chronic polyarthritis but without relapses of autoinflammation. These patients probably will need a switch in treatment to prevent further joint destruction.

\section{Acknowledgement}

supported by the BMBF (AID-Net 01GM0907)

Published: 14 September 2011

- No space constraints or color figure charges

- Immediate publication on acceptance

- Inclusion in PubMed, CAS, Scopus and Google Scholar

- Research which is freely available for redistribution 